\title{
YM-202204, a New Antifungal Antibiotic Produced by Marine Fungus Phoma sp.
}

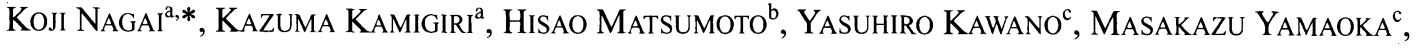 \\ Hitoshi SHIMOI $^{\mathrm{d}}$, MASATO WATANABE ${ }^{\mathrm{a}}$ and KENICHI SUZUKI ${ }^{\mathrm{a}}$ \\ ${ }^{a}$ Microbiology Laboratories, Institute for Drug Discovery Research, Yamanouchi Pharmaceutical Co., Ltd., \\ 1-1-8 Azusawa, Itabashi-ku, Tokyo 174-8511, Japan \\ ${ }^{\mathrm{b}}$ Analysis \& Metabolism Laboratories, Institute for Drug Discovery Research, Yamanouchi Pharmaceutical Co., Ltd., \\ 21 Miyukigaoka, Tsukuba-shi, Ibaraki 305-8585, Japan \\ ${ }^{\mathrm{c}}$ Research Institute of Biological Resources, National Institute of Advanced Industrial Science and Technology, Central 6, \\ 1-1-1 Higashi, Tsukuba, Ibaraki 305-8566, Japan \\ ${ }^{\mathrm{d}}$ National Research Institute of Brewing, \\ 3-7-1 Kagamiyama, Higashihiroshima, Hiroshima 739-0046, Japan
}

(Received for publication July 11, 2002)

\begin{abstract}
A new antifungal antibiotic, YM-202204 (1), was found in the culture broth of marine fungus Phoma sp. Q60596. The structure of 1 was determined by several spectroscopic experiments as a new lactone compound. This antibiotic exhibited potent antifungal activities against Candida albicans, Cryptococcus neoformans and Aspergillus fumigatus, and also inhibited glycosyl-phosphatidyl-inositol (GPI)-anchoring in yeast cells.
\end{abstract}

During the course of our screening for new antibiotics from the marine fungi, we found a new antifungal antibiotic YM-202204 (1) along with S39163/F-I (2) (Fig. 1) ${ }^{1)}$ from the culture broth of Phoma sp. Q60596 which was isolated from the marine sponge as an alkali-tolerant fungus. This antibiotic inhibited the growth of yeasts and fungi including pathogenic strains. Here we describe taxonomy of the producing organism, fermentation, isolation, physicochemical properties, structure elucidation and biological activity of the new antibiotic.

\section{Materials and Methods}

Isolation of Producing Organism

Marine sponge Halichondria japonica collected at Hoshisuna beach, Iriomote island, Okinawa Prefecture, Japan was used for the isolation of microorganisms. The sponge was cut into pieces ca. $5 \mathrm{~mm}$ in length. They were successively homogenized and suspended in sterile sea water. Fungi were isolated on cornmeal agar (CMA, pH 6.0; Nissui, Tokyo) and alkaline cornmeal agar (ACMA, $\mathrm{pH}$

Fig. 1. Structures of YM-202204 (1) and S39163/F-1 (2).

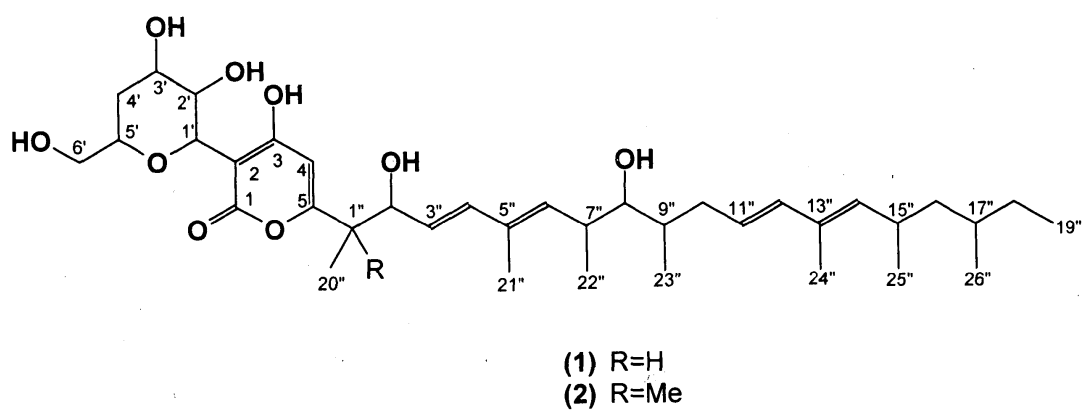

* Corresponding author: nagai@yamanouchi.co.jp 
ca. 9.7) by the dilution plate method ${ }^{2}$. The plates were incubated at $24^{\circ} \mathrm{C}$ for one to three weeks.

\section{Taxonomic Studies}

The following media were used for the identification of the fungus: potato dextrose agar (PDA), cornmeal agar (CMA), Miura's medium (LCA) and CZAPEK's agar. Morphological properties were observed under an optical microscope (Nikon OPTIPHOT-2). Growth rates at various $\mathrm{pH}$ were examined using the method of NAGAI et al. ${ }^{2}$.

\section{Fermentation}

A loopful of mycelia of strain Q60596 grown on an agar slant was inoculated into a 500-ml baffled Erlenmeyer flask containing $100 \mathrm{ml}$ of a seed medium consisting of glucose $1.0 \%$, potato starch $2.0 \%$, yeast extract $0.5 \%$, Polypepton (Nihon Pharmaceutical Co., Ltd.) $0.5 \%$ and $\mathrm{CaCO}_{3} 0.4 \%$. The $\mathrm{pH}$ of the medium was adjusted to 7.0 before sterilization. The seed culture was incubated at $24^{\circ} \mathrm{C}$ for 72 hours on a rotary shaker at $200 \mathrm{rpm}$. Two $\mathrm{ml}$ of the seed culture was transferred to each of thirty 500-ml Erlenmeyer flasks containing buckwheat flour $20.0 \mathrm{~g}$, cellulose $10.0 \mathrm{~g}$, yeast extract $0.05 \mathrm{~g}$, sodium tartrate $0.03 \mathrm{~g}, \mathrm{~K}_{2} \mathrm{HPO}_{4} 0.03 \mathrm{~g}$ and $80 \mathrm{ml}$ of distilled water. The $\mathrm{pH}$ of the medium was adjusted to 7.0 before sterilization. After inoculation flasks were incubated under static conditions for 15 days at $24^{\circ} \mathrm{C}$.

\section{Isolation}

Five hundred $\mathrm{ml}$ of acetone was added to each of thirty 500-ml flasks of solid fermentation and shaken for 10 minutes. The mixture was centrifuged at $8,000 \mathrm{rpm}$ for 15 minutes and then the supernatant was evaporated in vacuo. The aqueous solution was adjusted to $\mathrm{pH} 7.0$ and subjected to solid phase extraction with Diaion HP20. After having washed with $40 \%(\mathrm{v} / \mathrm{v})$ acetone aq., the column was eluted with $80 \%(\mathrm{v} / \mathrm{v})$ acetone aq. The elute was evaporated in vacuo to remove acetone, and the residual solution was extracted with 1-butanol at $\mathrm{pH}$ 7.0. The organic layer was dried, and chromatographed on silica gel using EtOAc $\mathrm{MeOH}(30: 70)$ as eluting solvent. Active fractions were collected and evaporated in vacuo. The yellow syrup was dissolved in methanol and applied to preparative HPLC (Lcolumn ODS; Simadzu, 20 i.d. $\times 250 \mathrm{~mm}$, flow rate; 8.0 $\mathrm{ml} /$ minute). The column was eluted with acetonitrile distilled water-trifluoroacetic acid $(72: 28: 0.05)$ to separate the peaks of $\mathbf{1}$ and $\mathbf{2}$. The yield of pure $\mathbf{1}$ was 27 mg.

Physico-chemical Properties and Structure Elucidation

IR spectra were recorded on a Perkin Elmer microscope
FT-IR spectrometer. Optical rotation was determined on Horiba SEPA-200 polarmeter. Fast atom bombardment mass spectra (FAB-MS) were obtained with a JEOL JMS700T using glycerol as matrix. ${ }^{1} \mathrm{H}$ and ${ }^{13} \mathrm{C}$ NMR spectra were recorded on a JEOL JNM-ALPHA500 FT NMR spectrometer.

\section{Bioassays}

Antifungal activity $\left(\mathrm{IC}_{80}\right)$ against Candida albicans ATCC10231, Cryptococcus neoformans TIMM0362, Aspergillus fumigatus TIMM1776 and Saccharomyces cerevisiae YFC805 was determined by a micro dilution method of KUME and YAMAZAKI ${ }^{3)}$.

HeLa S3 cells were cultured in RPMI-1640 supplemented with $10 \%$ fetal bovine serum and $20 \mathrm{mM}$ HEPES buffer. The cells were incubated in the presence or absence of the antibiotics at $37^{\circ} \mathrm{C}$ for 3 days in a humidified atmosphere containing $5 \% \mathrm{CO}_{2}$. Cytotoxicity on the cells was determined by a cell counting kit of Wako Pure Chemical Industries, Ltd.

Inhibition of glycosyl-phosphatidyl-inositol (GPI)anchored protein was measured by the following method. Saccharomyces cerevisiae YPH499 (Mata ura3-52 lys2-801 ade2-101 trp1- $\Delta 63$ his3- $\Delta 200$ leu2- $\Delta 1)^{4)}$ was used as a host for the expression of the following plasmid. Plasmid pMK1 contains a fusion gene encoding the full length of the Taka-amylase $\mathrm{A}^{5)}$ (TAA) and $C$-terminal 306 amino acid residues of a GPI-anchored protein Sed $1 \mathrm{p}^{6}$ ) (TAASed1). Releasing of GPI-anchored proteins into the agar medium is followed by a halo formation ${ }^{5,7)}$. GPI-anchored proteins released in the liquid medium were separated from cells by centrifugation at $3,000 \mathrm{rpm}$ for 10 minutes. TAA activity of the culture medium was measured with a kit of Kikkoman Co., Ltd.

\section{Results}

\section{Taxonomy of the Producing Strain}

Cultural and morphological characteristics of the strain Q60596 were as follows: colonies were fast-growing, reaching $35 \mathrm{~mm}$ in diameter in 14 days at $24^{\circ} \mathrm{C}$ on PDA, producing raised wooly mycelium. The color of the colonies was dark olive to dark gray and reverse side of the colonies was dark gray. Soluble pigment was not observed around colonies. The fungus produced dark brownish pycnidia, which were immersed into the medium. Pycnidia were mostly globose to subglobose, $100 \sim 250 \mu \mathrm{m}$ in diameter, with a single ostiole (Fig. 2A). Conidia were single-celled, hyaline, smooth, ellipsoidal to ovoid, $2.5 \sim 4 \times$ 
1.5 2 $2 \mathrm{~m}$ (Fig. 2B). Dark brownish chlamydospores were observed. The $\mathrm{pH}$ range for growth was 5.0 to 10.0 with an optimum $\mathrm{pH}$ range of 6.0 to 9.0 , which indicated this strain as an alkali-tolerant fungi.

Based on cultural and microscopic characteristics described above, strain Q60596 was considered to belong to the genus $P$ homa ${ }^{8)}$. The strain has been deposited in the National Institute of Advanced Industrial Science and Technology, Tsukuba, Japan, as Phoma sp. Q60596, with the accession No. FERM P-17526.

\section{Production and Isolation}

The production of $\mathbf{1}$ in the solid medium containing buckwheat flour and cellulose peaked after 15 days incubation at a titer of $1.2 \mathrm{mg} /$ flask. The $\mathrm{pH}$ of the media ( $\mathrm{pH} \mathrm{6,7,8}$ and 9) didn't affect the production of $\mathbf{1}$ (data not shown).

Solid culture (thirty 500-ml flasks) was extracted with acetone, then the aqueous solution was subjected to Diaion HP20 extraction and eluted with $80 \%$ (v/v) acetone aq. After the eluate was extracted with 1-butanol, the extract was chromatographed on a silica gel column to give a crude syrup. The syrup was purified by preparative HPLC using a column of ODS to give $\mathbf{1}$ as a yellow syrup.

\section{Physico-chemical Properties}

The molecular formula of $\mathbf{1}$ was determined to be $\mathrm{C}_{37} \mathrm{H}_{58} \mathrm{O}_{9}$ on the basis of positive-ion high resolution $\mathrm{FAB}-$ MS data $\left((\mathrm{M}+\mathrm{H})^{+} \mathrm{m} / \mathrm{z}\right.$ calcd: 647.4157 , found: 647.4158$)$. The IR spectral data had an absorption band at $3221 \mathrm{~cm}^{-1}$ indicating the presence of a hydroxyl group, and absorption bands at $1667 \mathrm{~cm}^{-1}, 1199 \mathrm{~cm}^{-1}$ and $1138 \mathrm{~cm}^{-1}$ indicating presence of an ester group. The physico-chemical prop-
Fig. 2. Optical micrograph of strain Q60596.

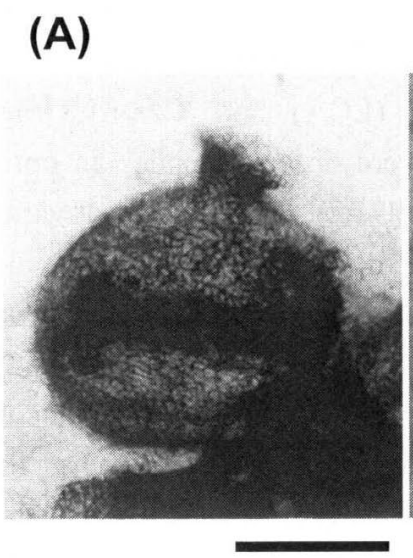

(B)

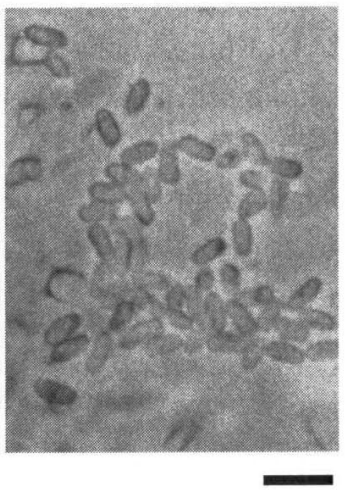

(A) Pycnidium. Bar represents $100 \mu \mathrm{m}$. (B) Conidia. Bar represents $5 \mu \mathrm{m}$. erties of 1 were shown in Table 1 .

\section{Structure Elucidation}

The ${ }^{13} \mathrm{C}$ NMR spectrum of $\mathbf{1}$ showed 37 carbon signals, which were assigned to eight methyl, five methylene, eighteen methine and six quaternary carbons by a DEPT experiment. The ${ }^{1} \mathrm{H}$ and ${ }^{13} \mathrm{C}$ NMR spectral data of $\mathbf{1}$ are summarized in Table 2. A ${ }^{1} \mathrm{H}-{ }^{1} \mathrm{H}$ DQF COSY experiment of 1 revealed four spin networks, from $1^{\prime}-\mathrm{H}$ to $6^{\prime}-\mathrm{H}$, from $4^{\prime \prime}$ $\mathrm{H}$ to $20^{\prime \prime}-\mathrm{H}$, from $6^{\prime \prime}-\mathrm{H}$ to $12^{\prime \prime}-\mathrm{H}$ and from $14^{\prime \prime}-\mathrm{H}$ to $19^{\prime \prime}-\mathrm{H}$ as shown in Fig. 3. From analysis of the heteronuclear multiple-bond correlation (HMBC) ${ }^{9)}$ spectrum, ${ }^{1} \mathrm{H}_{-}{ }^{13} \mathrm{C}$ long-range observed from $1^{\prime}-\mathrm{H}$ to $\mathrm{C}-5^{\prime}, \mathrm{C}-1, \mathrm{C}-2$ and $\mathrm{C}-3$, from $4^{\prime}-\mathrm{H}$ to $\mathrm{C}-2, \mathrm{C}-3, \mathrm{C}-5$ and $\mathrm{C}-1^{\prime \prime}$, from $21^{\prime \prime}-\mathrm{H}$ to $\mathrm{C}-4^{\prime \prime}$,

Table 1. Pysico-chemical properties of YM-202204 (1).

\begin{tabular}{ll}
\hline Appearance & Yellow syrup \\
{$[\alpha]_{\mathrm{D}}{ }^{25}$} & $-16(c 0.1, \mathrm{MeOH})$ \\
Molecular formula & $\mathrm{C}_{37} \mathrm{H}_{58} \mathrm{O}_{9}$ \\
FAB-MS $(m / z)$ & $647(\mathrm{M}+\mathrm{H})^{+}$ \\
HRFAB-MS $(m / z)$ & \\
$\quad$ calcd: & $647.4157(\mathrm{M}+\mathrm{H})^{+}$ \\
$\quad$ Found: & $647.4158(\mathrm{M}+\mathrm{H})^{+}$ \\
$\mathrm{UV} \lambda_{\max } \mathrm{nm}^{-1}(\varepsilon)($ in $\mathrm{MeOH})$ & $289(5,400), 236(32,000), 208(17,000)$ \\
IR $v_{\max } \mathrm{cm}^{-1}$ & $3221,2962,2926,1667,1583,1433,1199,1138,964,885$, \\
Solubility & 840,800 \\
$\quad$ soluble in & \\
$\quad$ insoluble in & EtOAc, MeOH, DMSO \\
\hline
\end{tabular}


Table 2. $\quad{ }^{1} \mathrm{H}$ NMR and ${ }^{13} \mathrm{C}$ NMR data of YM-202204 (1).

\begin{tabular}{|c|c|c|}
\hline Position & $\delta_{\mathrm{C}}^{\mathrm{a}}$ & $\delta_{\mathrm{H}}{ }^{\mathrm{b}}$ \\
\hline 1 & 167.2 & \\
\hline 2 & 100.4 & \\
\hline 3 & 170.9 & \\
\hline 4 & 102.3 & $6.08(\mathrm{~s})$ \\
\hline 5 & 168.9 & \\
\hline 1 ' & 75.7 & $4.49(\mathrm{~d}, J=9.8 \mathrm{~Hz})$ \\
\hline 2 ' & 73.5 & $4.01(\mathrm{t}, J=9.8 \mathrm{~Hz})$ \\
\hline 3 ' & 74.1 & $3.65(\mathrm{~m})$ \\
\hline 4' & 36.6 & 1.95 (ddd, $J=12.8,4.9,1.4 \mathrm{~Hz}), 1.56(\mathrm{~m})$ \\
\hline 5 , & 78.4 & $3.62(\mathrm{~m})$ \\
\hline $6^{\prime}$ & 65.7 & $3.57(2 \mathrm{H}, \mathrm{m})$ \\
\hline $1 "$ & 46.5 & $2.63(\mathrm{~m})$ \\
\hline 2" & 76.0 & $4.22(\mathrm{t}, J=8.2 \mathrm{~Hz})$ \\
\hline $3 "$ & 127.7 & $5.54(\mathrm{~m})$ \\
\hline $4 "$ & 139.3 & $6.31(\mathrm{~d}, J=15.9 \mathrm{~Hz})$ \\
\hline $5 "$ & 133.8 & \\
\hline $6 "$ & 136.1 & $5.60(\mathrm{~d}, J=9.8 \mathrm{~Hz})$ \\
\hline $7 "$ & 36.7 & $2.77(\mathrm{~m})$ \\
\hline 8" & 80.3 & $3.20(\mathrm{dd}, J=7.9,3.7 \mathrm{~Hz})$ \\
\hline 9" & 38.8 & $1.50(\mathrm{~m})$ \\
\hline $10 "$ & 37.0 & $2.46(\mathrm{~m}), 1.90(\mathrm{dt}, J=14.0,8.5 \mathrm{~Hz})$ \\
\hline $11 "$ & 126.7 & $5.53(\mathrm{~m})$ \\
\hline $12 "$ & 137.9 & $6.03(\mathrm{~d}, J=15.9 \mathrm{~Hz})$ \\
\hline $13 "$ & 133.3 & \\
\hline $14 "$ & 138.2 & $5.06(\mathrm{~d}, J=9.8 \mathrm{~Hz})$ \\
\hline $15 "$ & 31.3 & $2.59(\mathrm{~m})$ \\
\hline $16 "$ & 46.2 & $1.29,1.09(\mathrm{~m})$ \\
\hline $17 "$ & 33.6 & $1.26(\mathrm{~m})$ \\
\hline $18 "$ & 31.3 & $1.30,1.14(\mathrm{~m})$ \\
\hline $19 "$ & 11.7 & $0.86(3 \mathrm{H}, \mathrm{t}, J=7.0 \mathrm{~Hz})$ \\
\hline $20 "$ & 15.3 & $1.15(3 \mathrm{H}, \mathrm{d}, J=7.3 \mathrm{~Hz})$ \\
\hline $21 "$ & 13.0 & $1.79(3 \mathrm{H}, \mathrm{d}, J=1.2 \mathrm{~Hz})$ \\
\hline $22 "$ & 18.7 & $1.03(3 \mathrm{H}, \mathrm{d}, J=7.3 \mathrm{~Hz})$ \\
\hline $23 "$ & 16.4 & $0.81(3 \mathrm{H}, \mathrm{d}, J=6.7 \mathrm{~Hz})$ \\
\hline $24 "$ & 13.0 & $1.73(3 \mathrm{H}, \mathrm{s})$ \\
\hline $25 "$ & 22.1 & $0.93(3 \mathrm{H}, \mathrm{d}, J=6.7 \mathrm{~Hz})$ \\
\hline $26 "$ & 19.6 & $0.84(3 \mathrm{H}, \mathrm{d}, J=6.1 \mathrm{~Hz})$ \\
\hline
\end{tabular}

C-5" and C-6", from $24^{\prime \prime}-\mathrm{H}$ to $\mathrm{C}-12^{\prime \prime}, \mathrm{C}-13^{\prime \prime}$ and $\mathrm{C}-14^{\prime \prime}$ as shown in Fig. 3. The geometrical configuration of C-5" was determined to be $5^{\prime \prime} E$ by NOE observed between 7"-H and $21 "-\mathrm{H}$. The $13^{\prime \prime} E$ configuration was confirmed by NOEs observed between $12^{\prime \prime}-\mathrm{H}$ and $14^{\prime \prime}-\mathrm{H}$ and observed between $15^{\prime \prime}-\mathrm{H}$ and $24^{\prime \prime}-\mathrm{H}$. The $3^{\prime \prime} E$ and $11^{\prime \prime} E$ configuration were confirmed by coupling constants $(J=15.9 \mathrm{~Hz})$. Presence of an $\alpha$-pyrone was determined by comparison with the chemical shifts of carbons (C-1, C-2, C-3, C-4 and C-5) of dactylfungins $\mathrm{A}$ and $\mathrm{B}^{10)}$.
Biological Activities

Antifungal activity $\left(\mathrm{IC}_{80}\right)$ was determined by the micro dilution method ${ }^{3}$. The $\mathrm{IC}_{80} \mathrm{~s}$ of $\mathbf{1}$ against Candida albicans ATCC10231, Cryptococcus neoformans TIMM0362, Aspergillus fumigatus TIMM1776 and Saccharomyces cerevisiae YFC̣805 were $6.25 \mu \mathrm{g} / \mathrm{ml}, 1.56 \mu \mathrm{g} / \mathrm{ml}, 12.5$ $\mu \mathrm{g} / \mathrm{ml}$ and $1.56 \mu \mathrm{g} / \mathrm{ml}$, respectively. Cytotoxicity of 1 was examined against $\mathrm{HeLa} \mathrm{S} 3$ cells in vitro, and the $\mathrm{IC}_{50}$ value was $>100 \mu \mathrm{g} / \mathrm{ml}$.

We found 1 as the inhibitor of glycosyl-phosphatidylinositol (GPI)-anchoring. Inhibition of GPI-anchored 
Fig. 3. ${ }^{1} \mathrm{H}-{ }^{1} \mathrm{H} \mathrm{DQF}$ COSY, HMBC and NOE experiments of YM-202204 (1).

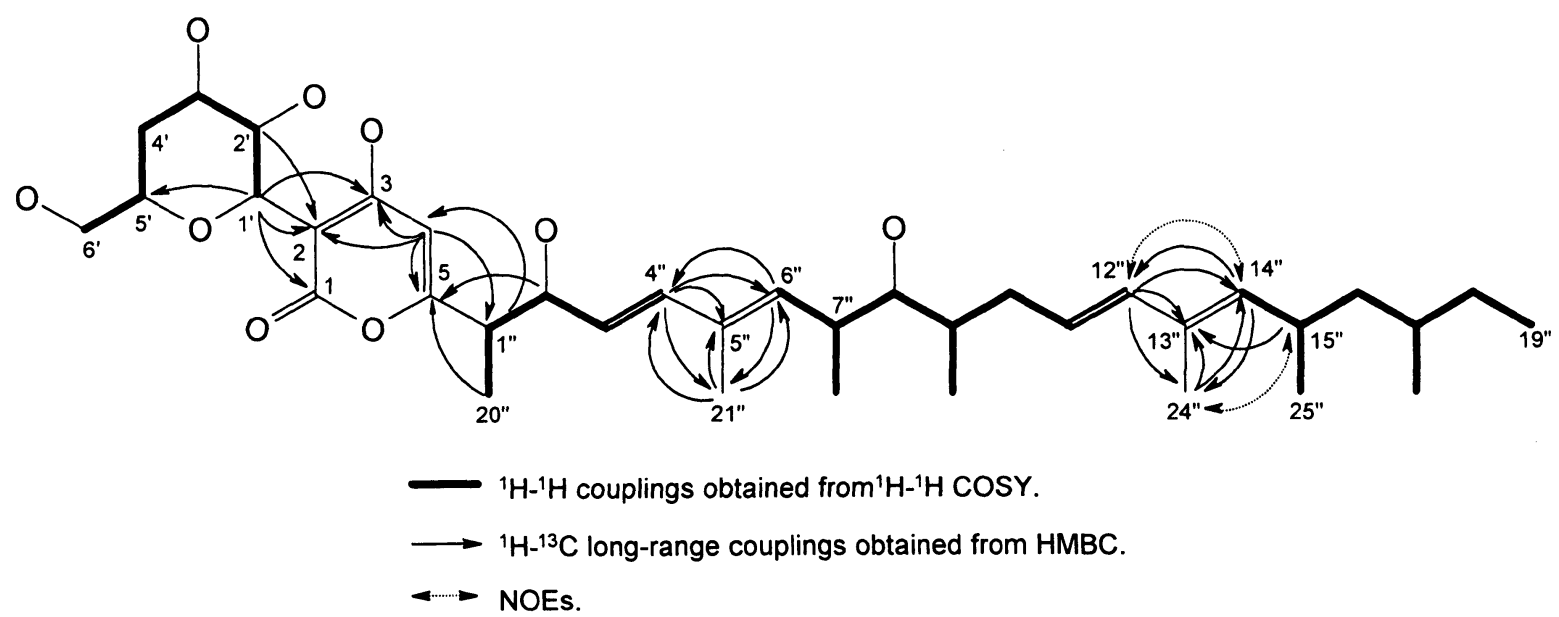

Table 3. TAA activity in the culture medium treated with YM-202204 (1).

\begin{tabular}{|c|c|c|c|}
\hline & \multicolumn{3}{|c|}{ Concentration $(\mu \mathrm{g} / \mathrm{ml})$} \\
\hline & 3 & 1 & 0 \\
\hline Time (hrs) & $\left(x 10^{-3}\right.$ & & \\
\hline 0 & 0.597 & 0.597 & 0.597 \\
\hline 1 & 8.95 & 4.30 & 0.537 \\
\hline 2 & 8.41 & 9.49 & 1.79 \\
\hline 4 & 14.0 & 11.8 & 4.83 \\
\hline 8 & 45.8 & 28.1 & 11.8 \\
\hline
\end{tabular}

proteins was measured by the method described in Materials and Methods. When S. cerevisiae YPH499 harboring pMK1 was cultured without the antibiotic, TAASed1 fusion proteins were localized in the cell wall. When S. cerevisiae YPH499 harboring pMK1 was cultured with 1 at $1.0 \mu \mathrm{g} / \mathrm{ml}$ for one hour, TAA activity of the culture medium containing 1 is 8 -fold higher than that of the liquid medium without 1 as shown in Table 3. This result suggested that 1 inhibited retention of TAA-Sedl fusion protein in the cell wall and released it into the culture medium.

\section{Discussion}

In this study, YM-202204 was isolated from the culture broth of marine fungus Phoma sp. Q60596. YM-202204 was shown to be a new member of the family of fungal products, which contain an $\alpha$-pyrone substituted with a polyalcohol and a long side chain. Examples of previously reported congeners are S39163/F-I (2), dactylfungins, fusapyrone $^{11)}$, deoxyfusapyrone, etc. ${ }^{12,13)}$. YM-202204 exhibited a relatively wide range of antifungal activities in vitro and inhibition of fungal GPI-anchoring activity. GPIanchoring represents a mechanism for attaching proteins to membranes that is used among all eucaryotic cells ${ }^{14)}$. Since GPI-anchored protein is essential for the growth of yeasts and fungi ${ }^{15,16)}$, this may be one of the unique targets for antifungal chemotherapy. Recently novel GPI-anchoring inhibitors, isolated from fungal broth, have been reported by the Novartis group ${ }^{17,18)}$. One of these compounds was known to block the addition of the third mannose to the 
intermediate structure Man2-GlcN-acylPI and inhibit GPIsynthesis in both $C$. albicans and in animal cells. Additional studies related the mechanism of action of YM202204 are being pursued.

\section{Acknowledgement}

This study was carried out as a part of the project for Technological Development of Biological Resources in Bioconsortia on R\&D of New Industrial Science and Technology Frontiers which was performed by Industrial Science, Technology and Environmental Policy Bureau, Ministry of Economy, Trade \& Industry, and entrusted by New Energy and Industrial Technology Development Organization (NEDO).

\section{References}

1) Tscher, H.; H. Hofman, R. Ewald \& M. M. Dreyfuss (Sandoz A. G.): Antibiotic lactone compound. U. S. 4,753,959, June 28, 1988

2) Nagai, K.; T. Sakai, R. M. Rantiatmodjo, K. Suzuki, W. Gams \& G. OKADA: Studies on the distribution of alkalophilic and alkali-tolerant soil fungi I. Mycoscience 36: 247 256, 1995

3) Kume, H. \& T. YAmazaKi: Practical measurement of antifungal activity. (in Japanese) Clinical Microbiology (JAPAN) 21: 572 580, 1994

4) SiKORSKI, R. S. \& P. HiETER: A system of shuttle vectors and yeast host strains designed for efficient manipulation of DNA in Saccharomyces cerevisiae. Genetics 122: 19 28, 1989

5) Nagashima, T.; S. Tada, K. Kitamoto, K. Gomi, C. KumAGAI \& H. TODA: Site-directed mutagenesis of catalytic active-site residues of taka-amylase A. Biosci. Biotech. Biochem. 56: 207 210, 1992

6) Shimoi, H.; H. Kitagaki, H. Ohmori, Y. Iimura \& K. ITO: Sedlp is a major cell wall protein of Saccharomyces cerevisiae in the stationary phase and is involved in lytic enzyme resistance. J. Bacteriol. 180: 3381 3387, 1998

7) Kambe-Honjoh, H.; K. Ohsumi, H. Shimoi, H. NAKAJIMA \& K. KiтAMOTO: Molecular breeding of yeast with higher metal-adsorption capacity by expression of histidine-repeat insertion in the protein anchored to the cell wall. J. Gen. Appl. Microbiol. 46: 113 117, 2000
8) Domsch, K. H.; W. Gams \& T-H. Anderson: Compendium of Soil Fungi. Vol. 1. pp. 630 643, IHWVerlag, 1993

9) BAX, A. \& M. F. Summers: ${ }^{1} \mathrm{H}$ and ${ }^{13} \mathrm{C}$ assignments from sensitivity-enhanced detection of heteronuclear multiplebond connectivity by $2 \mathrm{D}$ multiple quantum NMR. J. Am. Chem. Soc. 108: 2093 2390, 1975

10) Xaio, J.; S. Kumazawa, N. Yoshikawa, T. Milawa \& Y. SATO: Dactylfungins, novel antifungal antibiotics produced by Dactylaria parvispora. J. Antibiotics 46: $48 \sim 55,1993$

11) Altomare, C.; G. Perrone, M. C. Zonno, A. Evidente, R. Pengue, F. Fanti \& L. Polonelli: Biological characterization of fusapyrone and deoxyfusapyrone, two bioactive secondary metabolites of Fusarium semitectum. J. Nat. Prod. 63: 1131 1135, 2000

12) Breinholt, J.; C. N. Rosendahl \& H. Demuth (Novo Nordisk A/S): Fungicidally active compounds, their manufacture with Fusarium, and their use in timber, cosmetics, and feed or food. W. O. 9,322,444, November 11,1993

13) Chaiet, L.; S. Zimmerman, B. Sheldon, R. L. MONAGHAN \& G. M. GARRITY (Merck and Co., Inc.): Antifungal antibiotic from Fusarium. U. S. 5,008,187, April 16, 1991

14) McConville M. J. \& M. A. J. Ferguson: The structure, biosynthesis and function of glycosylated phosphatidylinositols in the parasitic protozoa and higher eukaryotes. Biochem. J. 294: 305 324, 1993

15) Leidich, S. D.; D. A. Drapp \& P. Orlean: A conditionally lethal yeast mutant blocked at the first step in glycosyl phosphatidylinositol anchor synthesis. J. Biol. Chem. 269: 10193 10196, 1994

16) Leidich, S. D.; Z. Kostova, R. R. Latek, L. C. Costello, D. A. Drapp, W. Gray, J. S. Fassler \& P. ORLEAN: Temperature-sensitive yeast GPI anchoring mutants gpi2 and gpi3 are defective in the synthesis of $\mathrm{N}$-acetylglucosaminyl phosphatidylinositol: cloning of the GPI2 gene. J. Biol. Chem. 270: 13029 13035, 1995

17) Sütterlin, C.; A. Horvath, P. Gerold, R. T. Schwarz, Y. WANG, M. DREYFUSS \& H. RiEZMAN: Identification of a species-specific inhibitor of glycosylphosphatidylinositol synthesis. Embo J. 16: 6374 6383, 1997

18) Wang, Y.; M. Dreyfuss, M. Ponelle, L. Oberer \& H. RIEZMAN: A glycosylphosphatidylinositol-anchoring inhibitor with an unusual tetracarbocyclic sesterterpene skelton from the fungus Codinaea simplex. Tetrahedron 54: 6415 6426, 1998 